\title{
Paradigma Keilmuan yang melandasi proses Transformasi Universitas Islam Negeri Walisongo Semarang
}

\author{
Yuli Supriani' ${ }^{1}$, Nanat Fatah Natsir ${ }^{2}$, Erni Haryanti ${ }^{3}$ \\ 1,2,3Universitas Islam Negeri Sunan Gunung Djati Bandung, Indonesia \\ E-mail: yulisupriani30@gmail.com, nanatfatahnatsir@uinsgd.ac.id, ernihk@uinsgd.ac.id
}

\begin{tabular}{l} 
Article Info \\
\hline Article History \\
Received: 2021-10-0 \\
Revised: 2021-11-02 \\
Published: 2021-11-29 \\
\\
Keywords: \\
Scientific Paradigm; \\
Transformation; \\
UIN; \\
The Walisongo.
\end{tabular}

The Walisongo.

\begin{abstract}
The purpose of this study was to determine the model of integrative scientific development at UIN Walisongo Semarang by carrying the Diamond Berlian Science model. The method used in this study uses a library research method or approach, that the study of literature or literature can be interpreted as a series of activities related to the methods of collecting library data, reading and recording and processing research materials. The results of this study indicate that the paradigm of unity of science developed by UIN Walisongo, namely by uniting all branches of science and providing the basis for revelation as a background or binder of unification. The idea of Islamization of science in the world of education in Indonesia is transformed in the realm of Islamic Religious Colleges which are the center of the development of Islamic science in the hope of accelerating the ideals of the Islamization of science in Indonesia. This has consequences for both State and Private Islamic Religious Universities, especially UIN Walisongo Semarang. One of the strategies for achieving unity of science or known as wahdat al-ulum is the transformation from IAIN to UIN.
\end{abstract}

\begin{tabular}{ll}
\hline Artikel Info & Abstrak \\
\hline Sejarah Artikel & Tujuan penelitian ini adalah untuk mengetahui model pengembangan keilmuan \\
Diterima: 2021-10-09 & integratif di UIN Walisongo Semarang dengan mengusung model Intan Berlian Ilmu. \\
Direvisi: 2021-11-02 & Metode yang digunakan dalam kajian ini menggunakan metode atau pendekatan \\
Dipublikasi: 2021-11-29 & $\begin{array}{l}\text { kepustakaan (library research), bahwa studi pustaka atau kepustakaan dapat diartikan } \\
\text { sebagai serangkaian kegiatan yang berkenaan dengan metode pengumpulan data }\end{array}$ \\
Kata kunci: & pustaka, membaca dan mencatat serta mengolah bahan penelitian. Hasil penelitian ini \\
Paradigma Keilmuan; & menunjukkan bahwa paradigma kesatuan ilmu pengetahuan (unity of science) yang \\
Transformasi; & dikembangkan UIN Walisongo, yakni dengan menyatukan antara semua cabang ilmu \\
UIN; & dan memberikan landasan wahyu sebagai latar atau pengikat penyatuan. Gagasan \\
Walisongo. & islamisasi ilmu pengetahuan dalam dunia pendidikan di Indonesia ditransformasi \\
& dalam ranah Perguruan Tinggi Keagamaan Islam yang menjadi sentral perkembangan \\
& ilmu keislaman dengan harapan dapat mempercepat cita-cita islamisasi ilmu \\
& pengetahuan di Indonesia. Hal ini memberikan konsekuensi terhadap Perguruan \\
& Tinggi Keagamaan Islam baik Negeri maupun Swasta, khususnya UIN Walisongo \\
& Semarang. Salah satu dari strategi pencapaian unity of science atau dikenal dengan \\
& wahdat al-ulum adalah transformasi dari IAIN menjadi UIN.
\end{tabular}

\section{PENDAHULUAN}

Perubahan zaman yang terjadi pada kehidupan dipengaruhi oleh pengetahuan. Menurut (Irwansyah, 2021) bahwa perkemba-ngan pengetahuan memberikan kontribusi lahirnya berbagai perubahan. Hal ini juga terjadi pada perubahan universitas islam di Indonesia, salah satunya adalah UIN Walisongo Semarang, pandangan mengenai model integrasi ilmu keislaman di kalangan cendekiawan muslim di Indonesia masih berserakan. Secara global jika kita amati hal tersebut masih tidak terumuskan dalam suatu pola pemikiran yang memiliki keunikan, sistematis, juga selaras. Selanjutnya diyakini bahwa perubahan beberapa Perguruan Tinggi Islam Negeri (PTKIN) yaitu Institut Agama
Islam Negeri (IAIN) dan Sekolah Tinggi Agama Islam Negeri (STAIN) menjadi Universitas, tidak memberikan gambaran tentang pemetaan atau pemetaan pemikiran ilmiah di Islam. Hal ini tidak terjadi hanya di Indonesia, tetapi di dunia Islam pada umumnya baik pada zaman klasik maupun modern. Itulah sebabnya banyak gagasan terkait integrasi keilmuan, termasuk juga yang bermuara pada perubahan bentuk IAIN maupun STAIN menjadi UIN menjadi sangat niscaya dalam rangka untuk memembangun sebuah tipologi integrasi keilmuan Islam (Thoyyar, 2009), menurut Yunus dalam (Hasbi, 2021) bahwa pandangan integrasi keilmuan dilator-belakangi oleh dikotomi antara agama dan sains. Dikotomi tersebut di antaranya terlihat dalam dikotomi 
lembaga pendidikan, yaitu adanya dikotomi antara pendidikan umum dan pendidikan keagamaan, yang hal tersebut telah terjadi sejak negara ini mengenal pola pendidikan modern. Dikotomi ilmu keislaman tersebut berdampak besar pada sisi-sisi dan bidang kependidikan di lingkungan umat Islam, hal ini baik yang terkait cara pandang umat terhadap ilmu dan pendidikan, kurikulum pendidikan, institusi pendidikan, maupun juga psikologi umat secara umum (Thoyyar, 2009).

Secara filosofis, penelitian ini penting untuk dilakukan mengingat upaya transformasi yang telah dilakukan oleh Institut Agama Islam Negeri Walisongo Semarang yang kini menjadi sebuah Universitas Islam Negeri. Penelitian ini kiranya akan dapat menjadi bahan acuan bagi UIN Walisongo Semarang untuk terus mendinamisasikan bangunan keilmuannya serta karakteristik pribadinya yang berbeda dengan UIN-UIN yang telah dan akan ada di Indonesia secara global tul ssan ini akan menjawab bagaimana bangunan ideal filsafat keilmuan UIN Walisongo Semarang dan model paradigma integrasi keilmuan UIN Walisongo Semarang. Tulisan ini adalah penelitian kepustakaan (library research) dan kualitatif.

\section{METODE PENELITIAN}

Sesuai dengan karakteristik masalah yang diangkat dalam penelitian ini maka penulis menggunakan Metode Riset kualitatif, yaitu menekankan analisanya pada data deskriptif berupa kata-kata tertulis yang diamati. Pendekatan kualitatif penulis gunakan untuk menganalisis paradigma keilmuan yang melandasi proses transformasi Universitas Islam Negeri Walisongo Semarang. Maka dengan sendirinya penganalisaan data ini lebih difokuskan pada Penelitian Kepustakaan (Library Research), yakni dengan membaca, menelaah dan mengkaji buku-buku dan sumber tulisan yang erat kaitannya dengan masalah yang dibahas. Metode yang digunakan dalam kajian ini menggunakan metode atau pendekatan kepustakaan (library research), menurut Zed dalam (Sofyan, 2020) bahwa studi pustaka atau kepustakaan dapat diartikan sebagai serangkaian kegiatan yang berkenaan dengan metode pengumpulan data pustaka, membaca dan mencatat serta mengolah bahan penelitian.

Jenis penelitian ini adalah penelitian kualitatif. Menurut Ibnu dalam (Arifudin, 2021) penelitian kualitatif adalah suatu penelitian yang datanya dinyatakan dalam bentuk verbal dan dianalisis tanpa menggunakan teknik statistik. Berdasarkan beberapa definisi penelitian kualitatif di atas, dapat disimpulkan bahwa penelitian kualitatif adalah suatu penelitian yang datanya dinyatakan dalam bentuk verbal, tidak menggunakan angka dan analisisnya tanpa menggunakan teknik statistik.

A. Objek Penelitian

Dalam penelitian ini objek penelitian, yaitu objek formal dan objek material. Objek formal dalam penelitian ini berupa data yaitu data yang berhubungan dengan paradigma keilmuan yang melandasi proses transformasi Universitas Islam Negeri Walisongo Semarang. Sedangkan objek materialnya berupa sumber data, dalam hal ini adalah buku-buku terkat keilmuan yang melandasi proses transformasi Universitas Islam Negeri Walisongo Semarang.

B. Waktu Penelitian

Penelitian ini dilaksanakan pada bulan Agustus sampai dengan Oktober tahun 2021.

C. Teknik Pengumpulan Data

Pengumpulan data yang dilakukan dengan menggunakan teknik dokumentasi yaitu mengadakan survey bahan kepustakaan untuk mengumpulkan bahan-bahan, dan studi literatur yakni mempelajari bahan-bahan yang berkaitan dengan objek penelitian. Teknik pengumpulan data menurut (Bahri, 2021) mengemukakan bahwa merupakan langkah yang paling strategis dalam penelitian karena tujuan untama dari penelitian adalah mendapatkan data. Terdapat beberapa cara atau teknik dalam mengumpulkan data, diantaranya adalah observasi dan dokumentasi, sumber data yang digunakan dalam penelitian ini mencakup data primer dan sekunder. Data primer adalah data yang dikumpulkan langsung dari individuindividu yang diselidiki atau data tangan pertama. Sedangkan data sekunder adalah data yang ada dalam pustaka-pustaka. Data primer dalam penelitian ini adalah buku paradigma keilmuan yang melandasi proses transformasi Universitas Islam Negeri Walisongo Semarang, dan data sekunder didapatkan dari jurnal-jurnal baik nasional maupun internasional.

D. Alat Pengumpulan Data

Dalam penelitian ini, penulis akan menggunakan metode dokumentasi sebagai alat untuk pengumpul data karena penelitian ini adalah penelitian kepustakaan, dengan kata lain, 
teknik ini digunakan untuk menghimpun datadata dari sumber primer maupun sekunder.

E. Teknik Analisis Data

Analisis data tidak saja dilakukan setelah data terkumpul, tetapi sejak tahap pengumpulan data proses analisis telah dilakukan. Penulis menggunakan strategi analisis "kualitatif", strategi ini dimaksudkan bahwa analisis bertolak dari data-data dan bermuara pada kesimpulan-kesimpulan umum. Berdasarkan pada strategi analisis data ini, dalam rangka membentuk kesimpulan-kesimpulan umum analisis dapat dilakukan menggunakan kerangka pikir "induktif". Menurut (Sugiyono, 2012) bahwa metode pembahasan menggunakan metode deskriptif-analisis, yaitu menjelaskan serta mengelaborasi ide-ide utama yang berkenaan dengan topik yang dibahas. Kemudian menyajikannya secara kritis melalui sumber-sumber pustaka primer maupun skunder yang berkaitan dengan tema.

F. Prosedur Penelitian

Data pada penelitian ini dicatat, dipilih dan kemudian diklasifikasikan sesuai dengan kategori yang ada. Pendekatan yang digunakan adalah pendekatan deskriptif analitis. Menurut (Rahayu, 2020) bahwa deskriptif analitis (descriptive of analyze research), yaitu pencarian berupa fakta, hasil dari ide pemikiran seseorang melalui cara mencari, menganalisis, membuat interpretasi serta melakukan generalisasi terhadap hasil penelitian yang dilakukan. Prosedur penelitian ini adalah untuk menghasilkan data deskriptif yang berupa data tertulis setelah melakukan analisis pemikiran (content analyze) dari suatu teks. Setelah penulis mengumpulkan bahan-bahan yang berhubungan dengan masalah yang akan di bahas dalam penelitian ini, kemudian penulis menganalisis dan menarasikan untuk diambil kesimpulan.

\section{HASIL DAN PEMBAHASAN}

A. Pentingnya Paradigma Dalam Pengembangan Ilmu Pengetahuan

Rene Descartes mengemukakan slogan Co Gito Ergo Sum timbullah dua pola pemikiran tentang ilmu pengetahuan. Pola pertama berkeyakinan bahwa tujuan sains adalah untuk menemukan kebenaran universal, dan kebenaran pengetahuan. Pola kedua disebut idealisme atau rasionalisme, yang mengatakan bahwa apa yang manusia ketahui tentang alam disekelilingnya telah disaring oleh panca indera. Jadi apa yang dianggap sebagai pengetahuan atau sebagai kebenaran adalah semata mata berdasarkan persetujuan di kalangan komunitas ilmiah dalam konteks sosial dan sejarah (Langgulung, 2002). Perbedaan dalam memahami sesuatu sebagai kebenaran, pada dasarnya sangat dipengaruhi oleh pandangan dunia dan sudut pandang yang digunakan oleh seseorang atau sekelompok orang (Arifudin, 2020).

Thomas Kuhn sebagai ilmuwan yang pertama kali mempopulerkan istilah paradigma dalam bukunya The Structure Scientific Revolution, dikutip dalam (Nasser, 2021) menggunakan istilah paradigma dalam dua dimensi yang berbeda, pertama, Paradigma mempunyai arti keseluruhan konstelasi kepercayaan (belief), nilai (values), teknik (techniques), dan sebagainya yang dimiliki bersama oleh anggota-anggota masyarakat ilmiah tertentu, Kedua, paradigma berarti unsur-unsur tertentu dalam perangkat tersebut, yakni cara-cara pemecahan masalah yang rumit, yang digunakan sebagai model atau contoh, yang dapat menggantikan model atau cara yang lain sebagai landasan pemecahan masalah dalam ilmu pengetahuan normal (normal science).

Menurut Kuhn, paradigma sangat berkaitan dengan tradisi ilmu pengetahuan yang telah mapan, yang sudah menjadi pola atau model yang di dalamnya memuat dalil, teori, penerapan dan instrumentasi. Konsep paradigm dalam pengertian Kuhn lebih menunjuk pada gugus berfikir, baik berupa model maupun pola yang digunakan oleh sekelompok komunitas ilmiah tertentu dalam upaya melakukan studi-studi keilmuan untuk memecahkan persoalan yang rumit yang mereka hadapi.

Paradigma, menurut Kuhn terdiri dari asumsi dan prinsip ontologis dan epitemologis khusus yang meliputi pula prinsipprinsip teoretis, yang berdasarkan prinsipprinsip tersebut teori-teori khusus yang dapat dibuktikan dan dibangun. Paradigma merupakan seperangkat konsep yang berhubungan satu sama lain secara logis, membentuk sebuah kerangka pemikiran, yang berfu-ngsi untuk memahami, menafsirkan dan menjelaskan kenyataan dan/ atau masalah yang dihadapi.

Paradigma merupakan suatu yang sudah ada, tumbuh dan berkembang dalam tradisi ilmu pengetahuan, dan diikuti oleh komunitas 
ilmiah. Suatu paradigma akan semakin kuat posisinya bila mampu memecahkan masalahmasalah keilmuan secara lebih berhasil dibandingkan dengan paradigma-paradigma yang lain. Komunitas ilmiah memandang paradigma yang lebih produktif apabila memiliki ketepatan, ruang lingkup, simplisitas, guna dan sebagainya yang lebih baik dari paradigma yang lain (Fedyani, 2005).

Kebenaran keilmuan yang sifatnya mutlak, melainkan selalu terdapat celah dalam sebuah gagasan terlebih lagi dalam ruang dan waktu yang berbeda. Maka akan ada peluang untuk lahirnya pengetahuan baru dengan epistemologi keilmuan yang terkadang lebih dapat diterima oleh masyarakat. Sehingga, dalam konteks keilmuan Islam menunjukkan bahwa Islam memiliki dasar pegangan alQur'an dan al-Hadits yang masih relevan sepanjang zaman sebagai kebenaran dan pedoman dalam hidup. Tetapi, apabila dalam perkembangannya muncul berbagai persoalan umat yang belum termaktub di dalam al-Qur'an dan al-Hadits, maka ilmuan muslim hendaklah terbuka dengan metodologi baru dalam memahami Islam dengan tetap berpegang teguh pada kebenaran al-Qur'an dan al-Hadits.

Metodologi baru dalam memahami Islam, tidak hanya terpaku pada pendekatan normatif saja, tetapi banyak pendekatan lain yang dapat digunakan seperti pendekatan historis, sosiologis, antropologis dan lain-lain. Sehingga, dengan berbagai metode dan pendekatan dalam studi Islam tersebut dapat memberikan kontribusi keilmuan yang dapat diterima oleh masyarakat sebagai bukti bahwa kebenaran Islam sebagai agama yang rahmatan lil alamin dan dapat diterima sepanjang zaman, tidak terbatas pada ruang dan waktu.

\section{B. Hakikat Ilmu Dalam Islam}

Pandangan Islam terhadap ilmu menjadi landasan bagi pengembangan ilmu disepanjang sejarah kehidupan umat Islam, sejak dari zaman klasik sampai sekarang. Nabi Muhammad SAW secara jelas menegaskan bahwa Ilmu Pengetahuan bersumber dari Allah serta menekankan bahwa Dia adalah sumber dan asal ilmu manusia, salah satu karya besar tentang usaha memahami akidah Islam adalah hadirnya karya Imam al-Ghazali Tahafut al-Falasifah. Hal tersebut juga telah mengundang banyak kritikan oleh para Mutakalimun dan Fuqaha. Mereka berpendapat terjadinya kemunduran dalam peradaban Islam disebabkan oleh kritikan oleh al-Ghazali yang telah mengkritik habis-habisan terhadap filsafat. Ibnu Rusyd juga menentang pemikiran Al-Ghazali dalam Tahafut alTahafut (Kerancuan kitab Tahafut). Hal yang demikian telah membuktikan bahwa filsafat merupakan ranah yang sangat diskursif dan dipengaruhi oleh proses dialektika dari waktu ke waktu.

Dominasi pemikiran al-Ghazali tersebut menyebabkan kejumudan pemikiran kefilsafatan di dunia Islam. Yang pada akhirnya menyebabkan memudarnya pembelajaran filsafat pada sebagian pendidikan yang berbasis agama Islam di Indonesia. Dapat dipahami bahwa dalam pemikiran Islam yang terjadi selama berabad-abad diakibatkan karena perbedaan landasan epistemology.

Menurut (Yazdi, 2003) berpendapat bahwa epistemologi merupakan awal tataran pada perbedaan antara pengetahuan melalui konsep atau konseptualisasi (al-ilm alhushuli) dan pengetahuan melalui kehadiran (al-ilm al hudhuri) kemudian memperluas maknanya. Dalam konteks epistemologi Islam, Muhammad Abed al-Jabiri dalam (Daud, 2015) juga memformulasikan tiga sistem pengetahuan yang berkembang dalam kebudayaan Islam, yaitu bayani, burhani, dan irfani. Kebenaran pengetahuan dapat disusun secara hierarki dari yang paling rendah kualitas kebenarannya hingga yang paling mutlak kebenarannya sebagaimana dalam gambar di bawah ini:

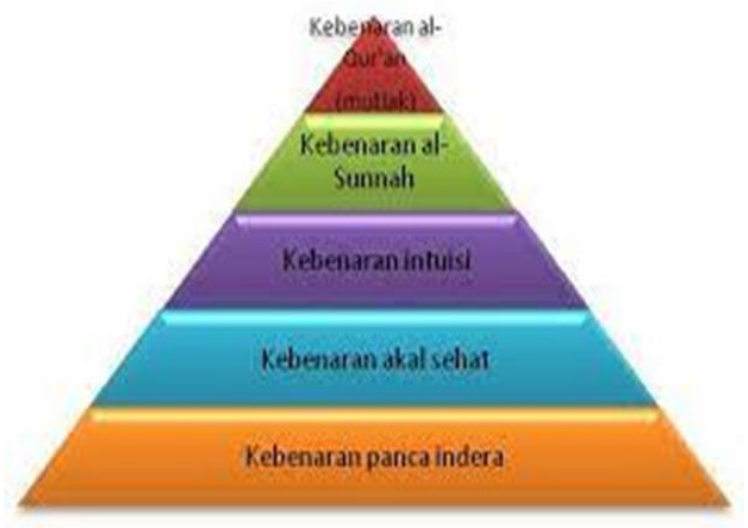

Gambar 1. Hierarki kebenaran pengetahuan dalam Islam

Dalam teori epistemologi Barat umumnya dikenal tiga hal yang menjadi sarana terciptanya pengetahuan, yaitu akal, indera dan intuisi. Sedangkan sumber pengetahuan dalam keilmuan Islam, yaitu teks (nash al- 
Qur'an), dan sumber lainnya hanya berfungsi sebagai pendukung bagi validitas teks, seperti contoh dalam perspektif pemikiran Islam, esensi ilmu selalu berangkat dari proposisi bahwa ilmu itu milik Allah SWT sebagai mana semua yang ada di alam ini. Hal itu menandakan bahwa ada kecenderungan sistem bayani dan lebih mengedepankan peran teks, yang mendasari sistem pemikiran Islam (Sibawaihi, 2004).

Wawasan al-Qur'an tentang ilmu pengetahuan pada hakikatnya bercorak Tauhid, yaitu kesatuan pandangan yang menegaskan adanya kesatuan sistem ilmu pengetahuan sebagai proses hubungan dialektis antara daya ruhaniah manusia dalam memahami ayat Tuhan, baik yang terkandung dalam alam, manusia, sejarah, maupun dalam kitab suci, mengenai sumber-sumber pengetahuan yang merupakan bahasan pertama dalam epistemologi, para filosof Islam menganggap bahwa realitas tidak hanya terbatas pada realitas yang bersifat fisik melainkan juga mengakui realitas yang bersifat non fisik. Oleh karena itu dalam epistemologi Islam kita mengenal realitas non fisik baik berupa realitas imajinal (mental) maupun realitas metafisika murni yang dibahas oleh para pemikir (Kartanegara, 2002).

Wahyu bisa juga dijadikan sebagai sumber pengetahuan, baik pada saat seseorang menemui jalan buntu ketika melakukan perenungan secara radikal maupun dalam kondisi biasa. Artinya wahyu bisa dijadikan sebagai rujukan pencarian pengetahuan kapan saja dibutuhkan, baik yang bersifat inspiratif maupun terkadang ada juga yang bersifat eksplisit (Daud, 2015). Wahyu ini secara hierarki terbagi menjadi tiga bagian; yaitu Al-Qur'an, al-Sunah dan intuisi. Maka sumber yang orisinil dari wahyu adalah alQur'an sebagai sumber pengetahuan utama dalam Islam dan al- Sunah sebagai sumber pengetahuan yang kedua, menurut Ghulsyani dalam bahwa wahyu itu sebagai petunjuk bagi manusia yang mengandung ilmu pengetahuan dan manusia itu diperintahkan untuk senantiasa menggunakan indera, akal, dan hatinya untuk menggali pengetahuan dari alam ini atas bimbingan wahyu itu sendiri (Siregar, 2021).

Islam meyakini bahwa sumber utama dari segala ilmu dan pengetahuan manusia dalam tak lain adalah wahyu Ilahi. Semua yang terkandung dalam wahyu adalah benar adanya, penilaian terhadap sesuatu hampir semuanya merujuk kepada wahyu. Dari sisi lain, wahyu menekankan pentingnya menjaga dan mempotensialkan ketiga sumber ilmu pengetahuan yang telah disebutkan pada pembahasan sebelumnya. Ketertinggalan dan kemunduran manusia dalam memeroleh ilmu pengetahuan tak lain disebabkan oleh diri manusia itu sendiri, yang lalai dan malas menggunakan segala potensi yang telah dianugerahkan kepadanya.

\section{Transformasi Universitas Islam Negeri Walisongo Semarang}

Gagasan dan perdebatan tentang kesatuan ilmu (the unity of science), pada dasarnya bukan gagasan baru dalam dunia filsafat. Guru pertama filsafat, Aristoteles abad ke-4 sebelum Masehi, (384-322 s.M) telah membahas masalah ini, seperti ditulis oleh C. A. Hooker. Ada sebuah ilmu tentang semua yang ada, metafisika, hal ini hanya merupakan prinsip-prinsip umum logika, dan ketidakleluasaan umum tentang sesuatu yang membuat logika yang secara jelas dapat diterapkan yakni, tidak ada dua hal dapat berada di tempat yang sama pada saat yang bersamaan. Menurut Hooker dalam (Juhji, 2020) bahwa manusia hidup dalam satu dunia alamiah, walaupun kompleks, dan pengetahuan ilmiah kita seharusnya berkaitan menjadi satu. Akan tetapi, saat ini ilmu pengetahuan secara kolektif membentuk sebuah struktur yang sangat kompleks, sebagiannya berkaitan dan sebagiannya tidak berkesesuaian. Bagaimana hal ini dijelaskan, dan apakan boleh kita berharap tentang kesatuan dalam ilmu pengetahuan.

Dari uraian Hooker tersebut, dapat dipahami bahwa filsafat sebagai akar ilmu pengetahuan tersusun dalam suatu struktur hierarkis yang meletakkan metafisika sebaga dasar yang daripadanya muncul beragam akar cabang. Dalam akar cabang metafisika inilah terletak teologi, ontologi, fisika, kosmologi, aksiologi, etika, estetika, logika, epistemologi, dan akar cabang filsafat lainnya. Semua akar cabang filsafat adalah dasar munculnya beragam teori yang lazim dikenal dengan sebutan ilmu pengetahuan (Mulkhan, 2002).

Guru kedua dalam filsafat Islam adalah AlFarabi, Gagasan kesatuan ilmu (the unity of science) secara jelas menurut Al-Farabi berangkat dari prinsip tauhid. Yang kemudian 
dikembangkan oleh para filsuf Muslim berikutnya dan hingga sampai pada para pemikir Islam di era modern, seperti Ismail Raji Al Faruqi, dan Muhamad Naquib Al-Attas, dan lain sebagainya. Dalam hal ini Zahra AlZeera menjelaskan bahwa salah satu karakteristik filsafat Islam klasik adalah pengetahuan para filsuf Muslim yang luas dan beraneka ragam, akan tetapi dalam waktu yang sama mereka mampu menyatukan keanekaragaman dan mampu mewujudkan kesatuan pengetahuan Tuhan (Al-Zeera, 2001). Dan inilah yang dilakukan oleh para pemikir Muslim kontemporer seperti AlFaruqi dan Al Attas serta Nasr yang ingin mengembalikan ilmu pengetahuan seperti ketika pada masa para filsuf Muslim. Demikian juga yang ingin diwujudkan oleh UIN Walisongo Semarang, yang berupaya untuk mewujudkan the unity of science.

Ismail Raji Al-Faruqi mengkampanyekan gerakan Islamisasi Ilmu Pengetahuan (The Islamization of knowledge), beliau menegaskan, bahwa keesaan mutlak Tuhan (tawhid) merupakan penegasan dari kesatupaduan sumber-sumber kebenaran. Tuhan adalah pencipta alam dari mana manusia memperoleh pengetahuannya. Obyek pengetahuan adalah pola-pola alam yang merupakan hasil karya Tuhan. Prinsip inilah merupakan dasar dari paradigma unity of science dalam khasanah filsafat Islam, atau epistemolgi Islam.

Secara epistemologis keilmuan Islam kontemporer, unity of science, oleh Syed Muhammad Naquib Al-Attas, dapat dianalogikan sebagai diri manusia, kemudian dikembangkan dalam bentuk universitas Islam, yang bersumber dari Al-Qur'an dan AlHadits, keduanya merupakan derivasi dari Tuhan. Dengan kata lain, pengetahuan Tuhan (God's knowledge) merupakan sumber semua ilmu pengetahuan manusia. Inilah yang menurut penulis merupakan inti dari paradigma the unity of science. Jadi, kesatuan ilmu pengetahuan atau the unity of science dapat dipahami sebagai keterkaitan erat atau kesatupaduan ilmu pengetahuan manusia, baik pada aspek ontologis, epistemologis maupun axiologis pengetahuan tersebut, dalam satu kesatuan kebenaran pengetahuan hakiki, dan tawhid sebagai landasan utamanya.

Al-Ghazali mendeklarasikan konsep holistik dan integratif. Pada dasarnya melibatkan semua aspek filsafat ilmu; yaitu ontologi, epistemologi dan aksiologi. Dalam sudut pandang ontologis, pengetahuan adalah salah satu sifat Allah. Dalam sudut pandang epistemologis, esensi dari pengetahuan adalah cahaya dan cahaya yang benar adalah Allah. Sedangkan dalam aspek axiologis, semua ilmu memiliki tujuan akhir yang sama. Al-Ghazali selalu mengumpulkan pengetahuan (al-'ilm), kondisi jantung (al-hal) dan tindakan (al'Amal) dalam satu konsep. Konsep al-Ghazali ini disebut Wahdat al-'Ulum (Unity of Sciences) (Muhaya, 2015).

Wahdat al-'Ulum berbeda dari islamisasi dan integrasi ilmu pengetahuan yang dipahami oleh Isma'il Raji al-Faruqi, Naquib al-Attas, Amin Abdullah dan lain-lain. Kedua islamisasi dan integrasi mengakui dikotomi ilmu pengetahuan. Islamisasi ilmu, integrasi dan interkoneksi adalah metode dan proses menuju kesatuan ilmu (Wahdat al-'Ulum). Abdul Muhayya menjelaskan bahwa konsep Wahdat Al-'Ulum bertumpu pada kebenaran dan keyakinan bahwa semua pengetahuan berasal dari Allah.

Wahdat al-'Ulum menyangkal pemisahan antara pengetahuan ilmiah dan agama. Wahdat al-'Ulum mengakui kecerdasan manusia dan wahyu sebagai sumber pengetahuan. Akibatnya, Wahdat al-'Ulum akan memimpin peradaban manusia selaras untuk kesejahteraan manusia, karena konsep Wahdat al-'Ulum membuat upaya serius untuk menyatukan semua aspek pengetahuan; epistemologi, ontologi dan aksiologi (Muhaya, 2015). Paradigma kesatuan Ilmu pengetahuan (the unity of science/ wahdat al-'Ulum), dengan demikian, merupakan sebuah tradisi keilmuan dalam masyarakat atau komunitas ilmiah di dunia Islam, yang dapat dijadikan sebagai model dalam pengembangan ilmu pengetahuan, untuk mengembangkan paradegma integrasi keilmuannya, UIN Walisongo merancang integrasi "Kesatuan Ilmu" (Unity of Sciences/Wahdat al-'Ulum) dengan model "Intan Berlian Ilmu", yang merupkan konsensus bersama komunitas ilmiah UIN Walisongo. Paradigma yang dimaksud dalam hal ini adalah bahwa semua disiplin ilmu harus saling berintegrasi dan saling sapa, karena pada dasarnya hal tersebut bersumber dari Allah secara langsung atau tidak langsung (Suharto, 2015). Dalam mengembangkan paradigma kesatuan ilmunya (Unity of Science), UIN Walisongo memegang prinsip- 
pinsip paradigma yaitu Integrasi, kolaborasi, dialektika, prospektif, dan pluralistik.

Ditengah hiruk-pikuk semangat dan tanggug jawab keilmuan perguruan tinggi, sebuah jargon "Kesatuan Ilmu" ini telah ditegaskan sebagai paradigma keilmuan institusi UIN Walisongo. Dalam paradigma ini, wahyu dipandang sebagai fondasi perekat bagi penyatuan ilmu pengetahuan. Ilmu selalu berproses dan berdialog menuju tujuan tunggal, yaitu Sang Pencipta yang Maha Tahu. Lulusan yang dihasilkan dari paradigma integrasi "Kesatuan Ilmu" ini adalah sosok pribadi yang komprehensif, yang mampu mengomunikasikan berbagai bidang ilmu dengan realitas. Paradigma integrasi "Kesatuan Ilmu" UIN Walisongo ini dapat digambarkan dengan model "Intan Berlian" yang cemerlang, berkilau dengan sinar indah, tajam, dan mencerahkan dengan lima sisi yang saling berkaitan. Berikut ditampilkan paradigma unity of science (wahdat al 'ilm) UIN Walisongo dengan ilustrasi "Intan Berlian Ilmu":

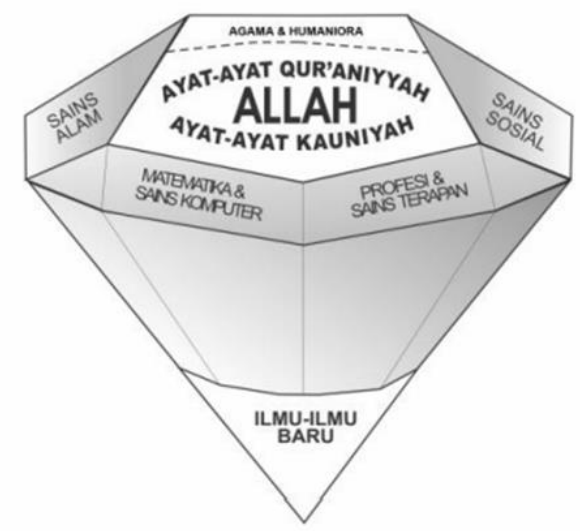

\section{Gambar 2. Ilustrasi Paradigma Unity of Science}

Dalam mengilustrasikan paradigma integrasi "Kesatuan Ilmu" UIN Walisongo dengan metapora "intan berlian", bahwa intan berlian itu sangat indah, mempunyai nilai yang tinggi dan mempunyai pancaran, memiliki sumbu dan sisi yang saling berhubungan satu sama lain. Sumbu paling tengah menggambarkan Allah sebagai sumber nilai, doktrin, dan ilmu pengetahuan. Allah menurunkan ayat-ayat Qur'aniyah dan ayat-ayat kauniyyah sebagai lahan eksplorasi pengetahuan yang saling melengkapi dan tidak mungkin saling bertentangan. Eksplorasi atas ayat-ayat Allah menghasilkan lima gugus ilmu, yaitu: 1) Ilmu
Agama dan Humaniora (religion and humanity sciences); 2) Ilmu-ilmu Sosial (social sciences); 3) Ilmu-ilmu Kealaman (natural sciences); 4) Ilmu Matematika dan Sains Komputer (mathematics and computing sciences); dan 5) Ilmu-ilmu Profesi dan Terapan (professions and applied sciences) (Tsuwaibah, 2014).

Dengan demikian Universitas Islam Negeri khususnya UIN Walisongo mempunyai misi menjadikan wahyu (al-Qur'an dan Sunnah) sebagai landasan atau basis bagi keilmuan yang dikembangkannya. Keilmuan ini telah dikembangkan oleh kaum Muslim periode Klasik. Pada periode ini, apapun keahlian seorang intelektual Muslim, baik dalam bidang ilmu-ilmu alam, ilmu-ilmu sosial ataupun humaniora, senantiasa menjadikan sumber ajaran Islam (Al-Qur'an dan Sunnah) sebagai basis dan landasan bagi spirit keilmuannya. Spirit ini pada gilirannya membawa intelektualisme Muslim mencapai era keemasannya, yang semuanya berkat semangat dan dorongan wahyu pertama, yang telah menjiwai kehidupan masyarakat.

\section{SIMPULAN DAN SARAN}

\section{A. Simpulan}

Untuk mengembangkan paradigma integrasi keilmuannya, UIN Walisongo merancang "Kesatuan Ilmu" (Unity of Science) dengan model "Intan Berlian Ilmu". Dalam mengembangkan paradigma unity of science, UIN Walisongo berpegang pada prinsipprinsip sebagai berikut : Integrasi, kolaborasi, dialektika, prospektif, dan pluralistic, model pengembangan keilmuan integratif UIN Walisongo digambarkan dengan model intan berlian bahwa intan berlian itu sangat indah, mempunyai nilai yang tinggi dan mempunyai pancaran, memiliki sumbu dan sisi yang saling berhubungan satu sama lain. Sumbu paling tengah menggambarkan Allah sebagai sumber nilai, doktrin, dan ilmu pengetahuan. UIN Walisongo menerapkan tiga model strategi untuk mengimplementasikan unity of science, yaitu: 1) Ilmu Agama dan Humaniora; 2) Ilmuilmu Sosial; 3) Ilmu-ilmu Kealaman; 4) Ilmu Matematika dan Sains Komputer; dan 5) Ilmuilmu Profesi dan Terapan.

\section{B. Saran}

Pembahasan paradigma keilmuan yang melandasi proses transformasi Universitas Islam Negeri Walisongo Semarang dalam penelitian ini masih sangat terbatas dan 
membutuhkan banyak masukan. Saran untuk penulis selanjutnya adalah mengkaji lebih dalam terkait paradigma keilmuan yang melandasi proses transformasi Universitas Islam Negeri Walisongo Semarang.

\section{DAFTAR RUJUKAN}

Arifudin, O. (2020). Psikologi Pendidikan (Tinjauan Teori Dan Praktis). Bandung: Widina Bhakti Persada.

Arifudin, O. (2021). Implementasi Balanced Scorecard dalam Mewujudkan Pendidikan Tinggi World Class. Edumaspul: Jurnal Pendidikan, 5(2), 767-775.

Bahri, A. S. (2021). Pengantar Penelitian Pendidikan (Sebuah Tinjauan Teori dan Praktis). Bandung: Widina Bhakti Persada.

Daud. (2015). Ilmu Pengetahuan dari John Locke ke Al-Attas. Jurnal Pencerahan, 9(1), 1-18.

Fedyani. (2005). Antropologi Kontemporer, Suatu Pengantar Kritis Mengenai Paradigma. Jakarta: Kencana.

Hasbi, I. (2021). Administrasi Pendidikan (Tinjauan Teori Dan Praktik). Bandung: Widina Bhakti Persada.

Irwansyah, R. (2021). Perkembangan Peserta Didik. Bandung : Widina Bhakti Persada.

Juhji. (2020). Manajemen Humas Sekolah. Bandung: Widina Bhakti Persada.

Kartanegara. (2002). Panorama Filsafat Islam. Bandung: Mizan.

Langgulung. (2002). Peralihan Paradigma Dalam Pendidikan Islam dan Sains Sosial. Jakarta: Gaya Media Pratama.

Muhaya. (2015). Unity of Sciences According to Al-Ghazali. Walisongo, 23(2), 327-338.

Mulkhan. (2002). Nalar Spiritual Pendidikan, Solusi Problem Filosofis Pendidikan Islam. Yogyakarta: Tiara Watjana.
Nasser, A. A. (2021). Sistem Penerimaan Siswa Baru Berbasis Web Dalam Meningkatkan Mutu Siswa Di Era Pandemi. Biormatika: Jurnal Ilmiah Fakultas Keguruan Dan Ilmu Pendidikan, 7(1), 100-109.

Rahayu, Y. N. (2020). Program Linier (Teori Dan Aplikasi). Bandung : Widina Bhakti Persada.

Sibawaihi. (2004). Eskatologi al-Ghazali dan Fazalur Rahman, Studi Komparatif Epistemologi Klasik Kontemporer. Yogyakarta: Islamika.

Siregar, R. T. (2021). Komunikasi Organisasi. Bandung: Widina Bhakti Persada.

Sofyan, Y. (2020). Peranan Konseling Dosen Wali Dalam Meningkatkan Motivasi Belajar Mahasiswa Di Perguruan Tinggi Swasta Wilayah LLDIKTI IV. Jurnal Bimbingan Dan Konseling Islam, 10(2), 237-242.

Sugiyono. (2012). Metode penelitian pendidikan. Bandung: Alfabeta.

Suharto. (2015). The Paradigm of TheoAnthropoCosmocentrism: Reposition of The Cluster of Non-Islamic Studies In Indonesian State Islamic Universities. Walisongo, 23(2), 270.

Thoyyar, H. (2009). Model-Model Integrasi Ilmu dan Upaya Membangun Landasan Keilmuan Islam. Forum Annual Internasional Conferrence of Islamic Studies (AICIS) Kementrian Agama Republik.

Tsuwaibah. (2014). Epistemologi Unity of Science Ibn Sina: Kajian Integrasi Keilmuan Ibn Sina dalam Kitab Asy-Syifa Juz I dan Relevansinya dengan Unity of Science IAIN Walisongo. Semarang: LP2M IAIN Walisongo Semarang.

Yazdi. (2003). Menghadirkan Cahaya Tuhan: Epistemologi Iluminasionis dalam Filsafat Islam. Bandung: Mizan. 